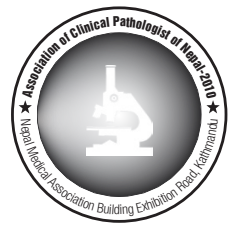

\title{
Beta thalassemia - a review
}

\author{
Jha $\mathrm{R}^{1}$, Jha $\mathrm{S}^{2}$ \\ ${ }^{l}$ Department of Pathology, Tribhuwan University Teaching Hospital, Kathmandu, Nepal \\ ${ }^{2}$ Department of Pathology, Manipal College of Medical Sciences, Pokhara, Nepal
}

\section{Keywords: \\ Beta Thalassemia; Carrier detection; Mutation; Prental diagnosis.}

\begin{abstract}
Thalassemia is a globin gene disorder that results in a diminished rate of synthesis of one or more of the globin chains. About $1.5 \%$ of the global population ( 80 to 90 million people) are carriers of beta Thalassemia. More than 200 mutations are described in beta thalassemia. However not all mutations are common in different ethnic groups. The only effective way to reduce burden of thalassemia is to prevent birth of homozygotes. . Diagnosis of beta thalassemia can be done by fetal DNA analysis for molecular defects of beta thalassemia or by fetal blood analysis. Hematopoietic stem cell transplantation is the only available curative approach for Thalassemia. Many patients with thalassemia in underdeveloped nations die in childhood or adolescence. Programs that provide acceptable care, including transfusion of safe blood and supportive therapy including chelation must be established.
\end{abstract}

\section{INTRODUCTION}

Thalassemia is the name given to a globin gene disorder that results in a diminished rate of synthesis of one or more of the globin chains and, consequently, a reduced rate of synthesis of the hemoglobin or hemoglobins of which that chain constitutes a part. ${ }^{1}$ Beta-thalassemia syndromes are a group of hereditary blood disorders characterized by reduced or absent beta globin chain synthesis. ${ }^{2}$ The condition was first described by Cooley and Lee in 1925. More than a decade later, Wintrobe and colleagues described milder form of Cooley's anemia in both parents of the children with classic Cooley's anemia. The word thalassemia is described from Greek word "thalas" meaning sea and "haimas" meaning blood because all early cases were reported in children of Mediterranean origin. ${ }^{1}$

\section{Correspondence:}

Dr Runa Jha, $M D$

Department of Pathology

Tribhuwan University Teaching Hospital

Maharajgunj, Kathmandu, Nepal,Email:runa75jha@yahoo.com
Types of Beta thalassemia

Different types of beta thalassemia are as follows: ${ }^{2}$

\section{Beta-thalassemia}

- $\quad$ Thalassemia major (Cooley's Anemia): refers to a severe clinical phenotype that occurs when patients are homozygous or compound heterozygous for more severe beta chain mutations (e.g. severe $\mathrm{B}+/ \mathrm{B}+$ mutations, $\mathrm{B}+/ \mathrm{B} 0, \mathrm{~B} 0 / \mathrm{B} 0$ )

- Thalassemia intermedia: An in between clinical phenotype with heterogeneous genetic mutations that still allow for some Beta chain production (e.g. B+/B0, $\mathrm{B}+/ \mathrm{B}+)$. Some rare cases also exist in which both beta and alpha mutations coexist

- Thalassemia minor (Beta Thalassemia carrier/trait): a mild clinical phenotype when one normal copy of the 
beta globulin gene is present (e.g. $\mathrm{B}+/ \mathrm{B}, \mathrm{B} 0 / \mathrm{B})$

- Beta-thalassemia with associated $\mathrm{Hb}$ anomalies

- $\quad H b C / B e t a-t h a l a s s e m i a$

- $\quad H b E / B e t a-t h a l a s s e m i a$

- HbS/Beta-thalassemia (clinical condition more similar to sickle cell disease than to thalassemia major or intermedia)

- Hereditary persistence of fetal $\mathrm{Hb}$ and betathalassemia

- Autosomal dominant forms

- Beta-thalassemia associated with other manifestations

- Beta-thalassemia-tricothiodystrophy

- $\quad$-linked thrombocytopenia with thalassemia

\section{Epidemiology}

Beta-thalassemia is prevalent in Mediterranean countries, the Middle East, Central Asia, India, Southern China and the Far East as well as countries along the north coast of Africa and in South America. The highest carrier frequency is reported in Cyprus (14\%), Sardinia (10.3\%) and Southeast Asia. $^{3}$ Population migration and intermarriage between different ethnic groups has introduced thalassemia in almost every country of the world. It has been estimated that about $1.5 \%$ of the global population ( 80 to 90 million people) are carriers of beta Thalassemia. However, accurate data on carrier rates in many populations are lacking, particularly in areas of the world known or expected to be heavily affected. ${ }^{4}$ Madan et al report overall carrier frequency of beta thalassemia carrier to be $4.05 \%$ and the birth incidence of beta thalassemia homozygotes to be 11,316 per year in India. ${ }^{5}$ WHO report estimates that $3 \%$ are carriers of beta thalassemia in Bangladesh. ${ }^{6}$ An estimated 5000-9000 children with beta thalassemia are born per year in Pakistan and the estimated carrier rate is 5 to $7 \%$, with 9.8 million carriers in the total population. ${ }^{7}$ Google search using term " beta thalassemia in Nepal" didn't show any published data that would indicate the burden of beta thalassemia in Nepal but unpublished hospital records of Tribhuwan University Teaching Hospital shows beta thalassemia more prevalent in the tharu community.

\section{Genetics of Beta thalassemia.}

More than 200 mutations are described in beta thalassemia. However not all mutations are common in different ethnic groups. The five common mutations found in Indian subcontinent are IVSI-1 $(\mathrm{G} \rightarrow \mathrm{T})$, IVSI-5 $(\mathrm{G} \rightarrow \mathrm{C})$, Del 619,
Fr 41-42(-TTCT) and Fr 8-9 (+G). In study by Satpute SB et al, IVS I-5 (G-C) mutation was detected in $65.07 \%$ followed by IVS I-1 (G-T) $(9.52 \%)$ in Indian population.8

$619 \mathrm{bp}$ deletion at the 3 ' end of beta-globin gene makes it nonfunctional. Frame shift mutations +1 codon $8 / 9(+\mathrm{G})$ and -4 codon $41 / 42$ (-TCTT) change the ribosome reading frame and causes premature termination of translation. Mutation IVS I-1 (G-T) causes change in splice junction causing ineffective RNA processing. IVS I-5 (G-C) destroys consensus sequences around splice junction which are essential for splicing. Mutation at codon $15(\mathrm{G}-\mathrm{A})$ causes a nonsense codon, terminating the synthesis of b-globin at a premature stage. ${ }^{9}$

\section{Hereditary transmission}

The beta thalassemias are inherited in an autosomal recessive manner. The parents of an affected child are obligate heterozygotes and carry a single copy of a disease causing beta globin gene mutation. At conception, each child of heterozygotes parents has $25 \%$ chance of being affected, $50 \%$ chance of being an asymptomatic carrier, and $25 \%$ chance of being unaffected and not carrier. ${ }^{2}$

\section{Pathophysiology}

The reduced amount $\left(\beta^{+}\right)$or absence $(ß 0)$ of beta globin chains result in a relative excess of unbound alpha globin chains that precipitate in erythroid precursors in the bone marrow, leading to their premature death and hence to ineffective erythropoiesis. The degree of globin chain reduction is determined by the nature of the mutation at the beta globin gene located on chromosome 11. Peripheral hemolysis contributing to anemia is less prominent in thalassemia major than in thalassemia intermedia, and occurs when insoluble alpha globin chains induce membrane damage to the peripheral erythrocytes. Anemia stimulates the production of erythropoietin with consequent intensive but ineffective expansion of the bone marrow (up 25 to 30 times normal), which in turn causes the typical bone deformities. Prolonged and severe anemia and increased erythropoietic drive also result in hepatosplenomegaly and extramedullary erythropoiesis. ${ }^{2}$

\section{Clinical Description}

Thalassemia major: Homozygotes for beta-thalassemia may develop either thalassemia major or thalassemia intermedia. Individuals with thalassemia major usually come to medical attention within the first 2 years of life and require regular blood transfusion to survive. Those presenting later do not require transfusion and receive a diagnosis of thalassemia intermedia. ${ }^{10}$

Affected infants with thalassemia major fail to thrive and become progressively pale. Feeding problems, diarrhea, 
irritability, recurrent bouts of fever and enlargement of the abdomen, caused by hepato splenomegaly, may occur. If a regular transfusion program that maintains a minimum $\mathrm{Hb}$ concentration of 9.5 to $10.5 \mathrm{~g} / \mathrm{dl}$ is initiated, then growth and development are normal until the age of 10 to 11 years. After the age of 10-11 years, affected individuals are at risk of developing severe complications related to post transfusion iron overload, depending on their compliance with chelation therapy. ${ }^{10}$ Survival of individuals who have been well transfused and treated with appropriate chelation may extend beyond the age of 30 years. Complications of iron overload in children include growth retardation and failure or delay of sexual maturation. Later iron overload related complications include involvement of the heart (dilated myocardiopathy or rarely arrythmias), liver (fibrosis and cirrhosis) and endocrine glands (diabetes mellitus, hypogonadism and insufficiency of the parathyroid, thyroid, pituitary, and, less commonly, adrenal glands). Myocardial disease caused by transfusional siderosis is the most important life-limiting complication of iron overload in beta thalassemia. Cardiac complications are reported to cause $71 \%$ of deaths in individuals with beta thalassemia major. ${ }^{11}$

The most relevant features of untreated or poorly transfused individuals are growth retardation, pallor, jaundice, brown pigmentation of the skin, poor musculature, genu valgum, hepatosplenomegaly, leg ulcers, development of masses from extramedullary hematopoiesis and skeletal changes that result from expansion of the bone marrow.

These skeletal changes include deformities of the long bones of the legs and typical craniofacial changes (bossing of the skull, prominent malar eminence, depression of the bridge of the nose, tendency to a mongoloid slant of the eye, and hypertrophy of the maxillae, which tends to expose the upper teeth). Individuals who have not been regularly transfused usually die before the third decade. ${ }^{10}$

The hemoglobin concentration, red blood cells (RBC), hematocrit (Hct), mean corpuscular volume (MCV), mean corpuscular hemoglobin $(\mathrm{MCH})$ and mean corpuscular hemoglobin concentration (MCHC) are reduced and red cell distribution width (RDW) is increased. The hemoglobin is usually in the range $3-7 \mathrm{~g} / \mathrm{dl}$, the MCV 50-60fl and the MCH 12-18pg. The blood film shows marked anisocytosis, poikilocytosis (including fragments and teardrop poikilocytes), hypochromia and microcytosis. Basophilic stippling, Pappenheimer bodies and target cells may be noted. Circulating nucleated red cells showing defective hemoglobinization and dyserythropoietic features are present. In children with massive splenomegaly, hypersplenism leads to aggravation of the anemia, neutropenia and thrombocytopenia. The absolute reticulocyte count is rarely high, although it tends to increase after splenectomy. If the spleen has been removed, the usual features of hyposplenism are present such as Howell-Jolly bodies, target cells, lymphocytosis, thrombocytosis and giant platelets. Pappenheimer bodies are very prominent and nucleated red cells are markedly increased. The bone marrow aspirate shows gross erythroid hyperplasia. There is quite severe dyserythropoiesis with nuclear lobulation and fragmentation, basophilic stippling, defective hemoglobinization and the presence of alpha chain precipitates. Actively phagocytic macrophages are prominent and pseudo-Gaucher cells are present. Iron stores are increased. ${ }^{1}$

Biochemical tests show increased bilirubin, increased urinary urobilinogen and hyperuricaemia. Haptoglobin is decreased or absent, free hemoglobin may be detectable in the plasma and methemalbumin may be present. ${ }^{1}$

In the case of homozygotes or compound heterozygotes for B0 Thalassemia (B0 B0), techniques such as hemoglobin electrophoresis and High performance liquid chromatography (HPLC) show only hemoglobin F and hemoglobin A2. In these cases $\mathrm{HbA}$ is absent, $\mathrm{HbF}$ is 95 $98 \%$ and $\mathrm{HbA} 2$ is $2-5 \%$ When there is homozygosity for $\mathrm{B}+$ thalassemia $(\mathrm{B}+\mathrm{B}+)$ or compound heterozygosity for $\mathrm{B} 0$ and $\mathrm{B}+$ thalassemia $(\mathrm{B}+\mathrm{B} 0)$, hemoglobin $\mathrm{A}$ is also present. Such cases show HbA between 10 and $30 \%, \mathrm{HbF}$ between $70-90 \%$ and $\mathrm{HbA} 2$ between $2-5 \% .^{10}$

Beta-thalassemia intermedia: Individuals with thalassemia intermedia present later than thalassemia major, have milder anemia and by definition do not require or only occasionally require transfusion. At the severe end of the clinical spectrum, patients present between the ages of 2 and 6 years and although they are capable of surviving without regular blood transfusion, growth and development are retarded. At the other end of the spectrum are patients who are completely asymptomatic until adult life with only mild anemia. ${ }^{2}$

Principle symptoms are pallor, jaundice, cholelithiasis, liver and spleen enlargement, moderate to severe skeletal changes, leg ulcers, extramedullary masses of hyperplastic erythroid marrow, a tendency to develop osteopenia and osteoporosis and thrombotic complications. ${ }^{12,13}$ Patients with thalassemia intermedia have an increased predisposition to thrombosis as compared to thalassemia major, especially if splenectomised. Such events include deep vein thrombosis, portal vein thrombosis, stroke and pulmonary embolism. ${ }^{14}$ Although individuals with thalassemia intermedia are at risk of iron overload secondary to increased intestinal iron absorption, hypogonadism, hypothyroidism and diabetes are not common. ${ }^{15}$

Patients with thalassemia intermedia have a moderate anemia and show a markedly heterogeneous hematological picture, ranging in severity from that of the beta-thalassemia carrier state to that of thalassemia major. ${ }^{10}$ Flow chart for the 


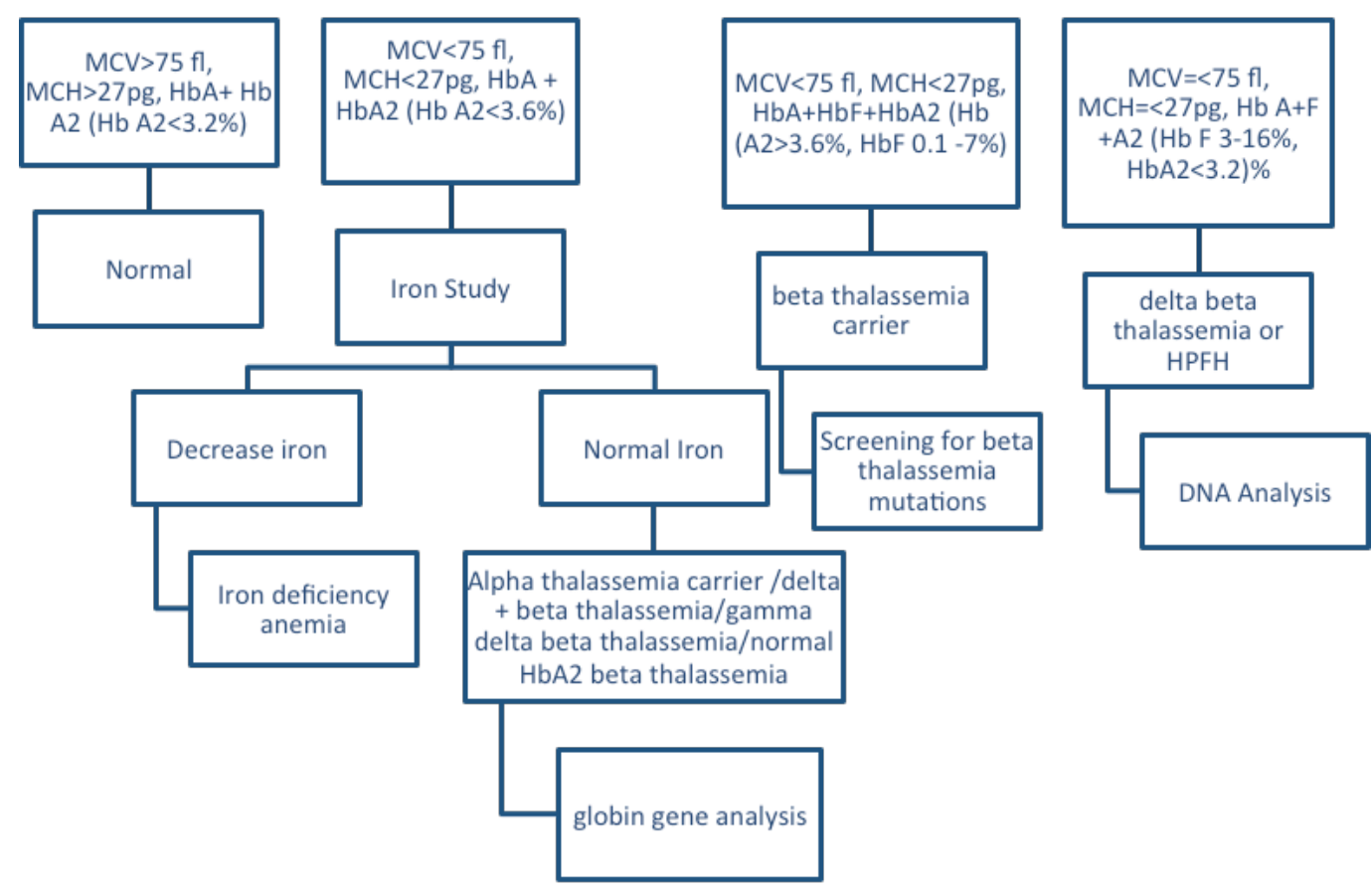

Figure 1: Flow chart for carrier identification of beta Thalassemia

identification of $\beta$ Thalassemia is shown in figure 1 .

\section{Beta-thalassemia carrier state/Thalassemia Minor:}

Carriers of beta-thalassemia are clinically asymptomatic. The characteristic hematological features are microcytosis, hypochromia and increased $\mathrm{HbA} 2$ level. ${ }^{10}$

The blood count characteristically shows a normal or slightly reduced hemoglobin concentration, elevation of the $\mathrm{RBC}$ and reduction of the $\mathrm{MCH}$ and $\mathrm{MCV}$. The $\mathrm{MCHC}$ is usually normal. The red cell distribution width (RDW) is usually normal. Mean values for hematological variables (hemoglobin concentration, $\mathrm{MCV}$ and $\mathrm{MCH}$ ) differ significantly between $\beta+$ and $\beta 0$ Thalassemia trait, but there is considerable overlap. The hemoglobin concentration falls in pregnancy as the plasma volume rises .When a patient with $\beta$ Thalassemia trait develops megaloblastic anemia or significant liver disease, the MCV and $\mathrm{MCH}$ may rise into the normal range. The same will occur with the administration of drugs such as zidovudine or hydroxycarbamide. ${ }^{1}$

The blood film varies from almost normal with only mild microcytosis to markedly abnormal. Abnormal features, in addition to microcytosis, include anisocytosis, hypochromia and poikilocytosis. Individuals with a more severe phenotype may have prominent basophilic stippling, target cells and small numbers of irregularly contracted cells. Some thalassemic individuals have prominent elliptocytes. The percentage of reticulocytes may be slightly elevated.
The bone marrow aspirate shows increased cellularity as a consequence of erythroid hyperplasia. Some erythroblasts show defective hemoglobinization and cytoplasmic vacuolation. $^{1}$

An iron stain may show heavy siderotic granulation. In the neonatal period, babies with beta Thalassemia trait, in contrast with those with alpha Thalassemia trait, have a normal hemoglobin concentration and normal red cell indices. Differences from normal start to appear around the age of 3 months. ${ }^{1}$

\section{Diagnosis}

Clinical diagnosis: Thalassemia major is usually suspected in an infant younger than two years of age with severe microcytic anemia, mild jaundice and hepatosplenomegaly. Thalassemia intermedia presents at a later age with similar but milder clinical findings. Carriers are usually asymptomatic, but sometimes may have mild anemia.

Hematologic Diagnosis: RBC indices show microcytic anemia. Thalassemia major is characterized by reduced Hb level $(<7 \mathrm{~g} / \mathrm{dl}), \mathrm{MCV}>50<70 \mathrm{fl}$ and $\mathrm{MCH}>12<20$ pg. Thalassemia intermedia is characterized by $\mathrm{Hb}$ level between 7 and $10 \mathrm{~g} / \mathrm{dl}, \mathrm{MCV}$ between 50 and $80 \mathrm{fl}$ and $\mathrm{MCH}$ between 16 and $24 \mathrm{pg}$. Thalassemia minor is characterized by reduced $\mathrm{MCV}$ and $\mathrm{MCH}$, with increased $\mathrm{Hb} \mathrm{A} 2$ level. ${ }^{2}$ 


\begin{tabular}{|c|c|c|c|c|}
\hline ANALYTE & ID & $\%$ & TIME & AREA \\
\hline P2 & & 5.4 & 1.29 & 116691 \\
\hline P3 & & 4.1 & 1.63 & 88794 \\
\hline Ao & & 87.3 & 2.34 & 1876153 \\
\hline A2 & & 2.8 & 3.54 & 47765 \\
\hline Unknown & 1 & 0.6 & 4.76 & 11893 \\
\hline & \multicolumn{3}{|c|}{ TOTAL AREA } & 2141296 \\
\hline & & $0.0 \%$ & & $2.8 \%$ \\
\hline
\end{tabular}

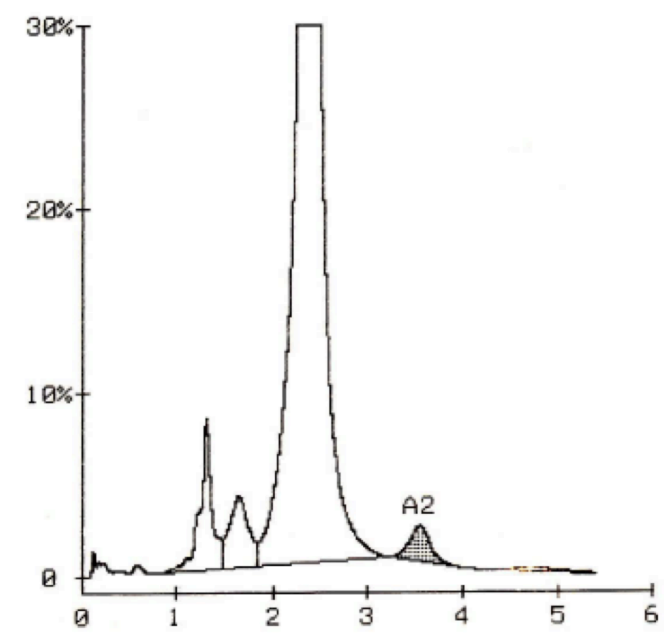

Figure 2 a: HPLC pattern in normal subjects

Peripheral blood smear: Affected individuals show RBC microcytosis, hypochromia, anisocytosis, poikilocytosis (spiculated tear-drop and elongated cells) and nucleated RBC (i.e., erythroblasts). The number of erythroblasts is related to the degree of anemia and is markedly increased after splenectomy. Carriers have less severe RBC morphologic changes than affected individuals. Erythroblasts are normally not seen. ${ }^{10}$

HPLC/electrophoresis: The $\mathrm{Hb}$ pattern in beta-thalassemia varies according to beta-thalassemia type. In $\beta 0$ thalassemia homozygotes $\mathrm{HbA}$ is absent and $\mathrm{HbF}$ constitutes the 92$95 \%$ of the total $\mathrm{Hb}$. In beta+ thalassemia homozygotes and $\mathrm{B}+/ \mathrm{BO}$ genetic compounds $\mathrm{HbA}$ levels are between 10 and $30 \%$ and $\mathrm{HbF}$ between 70 to $90 \%$. $\mathrm{HbA} 2$ is variable in beta thalassemia homozygotes and it is enhanced in beta thalassemia minor. ${ }^{10}$ Figure $2 a$ and $2 b$ shows the HPLC pattern in normal individual and patient with $\beta$ Thalassemia trait. $\mathrm{Hb}$ electrophoresis pattern in various conditions is shown in figure 3.

Molecular Genetic Analysis: A limited number of molecular defects are prevalent in every at risk population. This may be very useful in practice, because a panel of most frequent mutations to be searched for can be designed according to the carrier's ethnic origin. Known mutation detection is carried out by a number of polymerase chain reaction (PCR) based techniques. Among them, the most commonly used are the primer-specific amplification (ARMS, Amplification Refractory Mutation System) and the reverse oligonucleotide hybridisation with specific oligonucleotide probes (RDB, Reverse Oligonucleotide-probe analysis. If targeted mutation analysis fails to detect the mutation, beta globin gene sequence analysis can be used to detect unknown mutations in the beta globin gene ) ${ }^{16}$

\section{Dominant Beta thalassemia}

Most individuals who are heterozygous for a beta Thalassemia mutation have clinicopathological features described as 'Thalassemia minor', i.e. the blood count and film are abnormal but there are no abnormal physical findings or symptoms. However, some mutations produce clinically apparent abnormalities in heterozygotes, mainly splenomegaly, anemia, jaundice and an increased incidence of gallstones. This is referred to as dominant beta thalassemia. ${ }^{1}$ Dominant beta Thalassemia is rare, but cases are found scattered throughout the world. The clinicopathological features are those of Thalassemia intermedia. Red cell survival is less than in typical Beta Thalassemia trait and the reticulocyte count is increased. Patients may require occasional blood transfusions. There is extramedullary hemotopoiesis and iron overload may occur. The blood film is usually very abnormal with prominent basophilic stippling and circulating nucleated red cells. The bone marrow shows erythroid hyperplasia and dyserythropoiesis . ${ }^{1}$

\section{Problems linked to diagnosis of beta thalassemia trait}

The best approach to screen the Thalassemia traits is determining the $\mathrm{Hb} \mathrm{A} 2$ level. The large majority of beta thalassemia carriers present with a high $\mathrm{Hb} \mathrm{A} 2$ level and this often accompanied by moderate increase in $\mathrm{Hb} F$ level . $\mathrm{The} \mathrm{Hb} \mathrm{A} 2$ level may be modified by many factors.

Nutritional anemia: Iron deficiency lowers the hemoglobin A2 percentage both in individuals with no defect of globin genes and in those with Thalassemia trait. it is preferable not to attempt to exclude a diagnosis of $b$ Thalassemia trait in patients with severe or moderately severe iron deficiency, but rather to correct the iron deficiency and then measure the hemoglobin A2 percentage if the red cell indices do not return to normal. An exception to this generalization is in the case of pregnant women in whom a diagnosis of beta Thalassemia trait is required without delay. In such circumstances, it may be necessary to measure hemoglobin A2 in the partner and, if he is found to have beta Thalassemia trait, to consider proceeding to molecular analysis in women with borderline hemoglobin A2 percentages. Folic acid deficiency can also lower the percentage of hemoglobin A2 and interfere with the diagnosis of beta Thalassemia trait. ${ }^{1}$

Coinheritance of other Hemoglobinopathies: In beta 


\begin{tabular}{|c|c|c|c|c|}
\hline ANALYTE & ID & $\%$ & TIME & AREA \\
\hline $\mathrm{F}$ & & 8.4 & 1.12 & 146914 \\
\hline P2 & & 3.9 & 1.29 & 65767 \\
\hline P3 & & 4.2 & 1.64 & 70198 \\
\hline Ao & & 77.9 & 2.37 & 1315634 \\
\hline A2 & & 4.9 & 3.56 & 67100 \\
\hline Unknown & 1 & 0.8 & 4.74 & 13136 \\
\hline \multicolumn{4}{|c|}{ TOTAL AREA } & 1678749 \\
\hline $\mathrm{F}$ & & $8.4 \%$ & & $4.9 \%$ \\
\hline
\end{tabular}

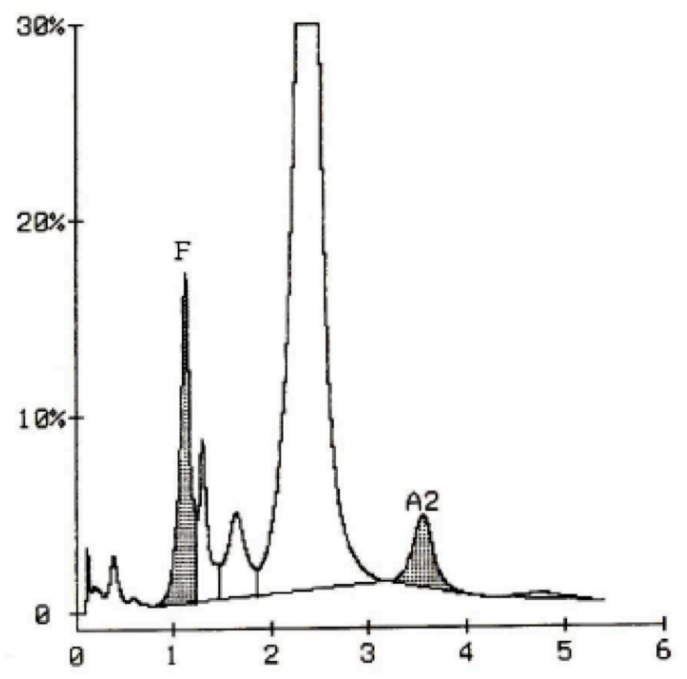

Figure 2b: HPLC pattern in Thalassemia trait

Thalassemia carriers presenting with a normal $\mathrm{HbA} 2$ level, another cause is a co-inherited $\delta$ globin abnormality. ${ }^{17}$ Hemoglobin Knossus, a 'thalassemic hemoglobinopathy', is also responsible for some cases of beta Thalassemia trait with normal hemoglobin A2. When an individual has both hemoglobin $\mathrm{H}$ disease and beta Thalassemia heterozygosity, the hemoglobin A2 may be normal. ${ }^{1}$

Conversely, falsely increased levels of $\mathrm{HbA} 2$ may result from the co-existence of a variant with electrophoretic or chromatographic properties close to that of $\mathrm{HbA} 2$. As a rule, this situation has to be verified when a level of $\mathrm{HbA} 2$ higher than 8 percent is observed. The presence of a Thalassemia will generally be ruled out by considering hematological data showing absence of microcytosis and hypochromia. Nevertheless, two common variants, which elute on CE$\mathrm{HPLC}$ in the $\mathrm{HbA} 2$ window, are really thalassemic $\mathrm{Hb}$. The first one is $\mathrm{HbE}$, frequent in populations from South East Asia, and the second is $\mathrm{Hb}$ Lepore. Since many other thalassemic defects are present in the same populations as $\mathrm{HbE}$, a large variety of clinical phenotype associated with $\mathrm{HbE}$ is observed. These range from very mild ones, the simple heterozygous state for $\mathrm{HbE}$, to severe ones, which associate $\mathrm{HbE}$ to $\beta 0$ thalassaemia. ${ }^{18}$
Neonates: Beta Thalassemia cannot be diagnosed from the hemoglobin A2 percentage in neonates as levels are low. However, by 6-12 months of age, the average hemoglobin A2 percentage is higher than in other infants. ${ }^{1}$

Silent and almost silent beta thalassemia: There are beta gene mutations that can cause clinically significant disease in homozygotes and compound heterozygotes. These mutations are divided into into two groups: 'silent beta Thalassemia trait' and 'almost silent beta thalassemia trait'. In silent beta thalassemia trait, both the red cell indices and the haemoglobin A2 percentage are normal. Most of these cases are missed in the routine diagnostic laboratory. In almost silent beta Thalassemia trait, the red cell indices are abnormal but the hemoglobin A2 percentage is not increased. ${ }^{10}$

\section{Differentiating Beta Thalassemia from iron deficiency anemia}

Differentiation between iron deficiency anemia and thalassemia trait may pose problem. If serum iron, ferritin and $\mathrm{HbA} 2$ levels are known it will help. Indices derived from automated hematology analyzer may also help in rapid differentiation of microcytosis of thalassemia and iron deficiency anemia. Formula suggested by England and Fraser is (Derived factor, DF=MCV-RBC- $(5 \mathrm{xHb})$ divided by 3.4). Values over 2 are seen with iron deficiency anemia where as values less than indicate thalassemia trait.19 Other ratios suggested are Mentzer ratio, Srivastava Ratio and Shine and Lal product. ${ }^{20}$

\section{Beta-thalassemia associated with $\mathrm{HbE}$ anomalies}

The interaction of $\mathrm{HbE}$ and beta-thalassemia results in thalassemia phenotypes ranging from a condition indistinguishable from thalassemia major to a mild form of thalassemia intermedia. Depending on the severity of symptoms three categories may be identified: ${ }^{2}$

- Mild HbE/beta-thalassemia: It is observed in about $15 \%$ of all cases in Southeast Asia. This group of patients maintains $\mathrm{Hb}$ levels between 9 and $12 \mathrm{~g} / \mathrm{dl}$ and usually does not develop clinically significant problems. No treatment is required.

- Moderately severe HbE/beta-thalassemia: The majority of $\mathrm{HbE} /$ beta-thalassemia cases fall into this category. The $\mathrm{Hb}$ levels remain at 6-7 $\mathrm{g} / \mathrm{dl}$ and the clinical symptoms are similar to thalassemia intermedia. Transfusions are not required unless infections precipitate further anemia.

- Severe HbE/beta-thalassemia: The Hb level can be as low as 4-5 g/dl. Patients in this group manifest symptoms similar to thalassemia major and are treated as thalassemia major patients. 


$\begin{array}{lrrr}\text { ANALYTE ID } & \% & \text { TIME } & \text { AREA } \\ \text { F } & 81.6 & 1.20 & 1100637 \\ \text { AO } & 8.9 & 2.46 & 113270 \\ \text { A2 } & 4.6 & 3.56 & 46593 \\ & \text { TOTAL AREA } & 1260500 \\ & \text { F1.6\% } & \text { A2 } & 4.6 \%\end{array}$

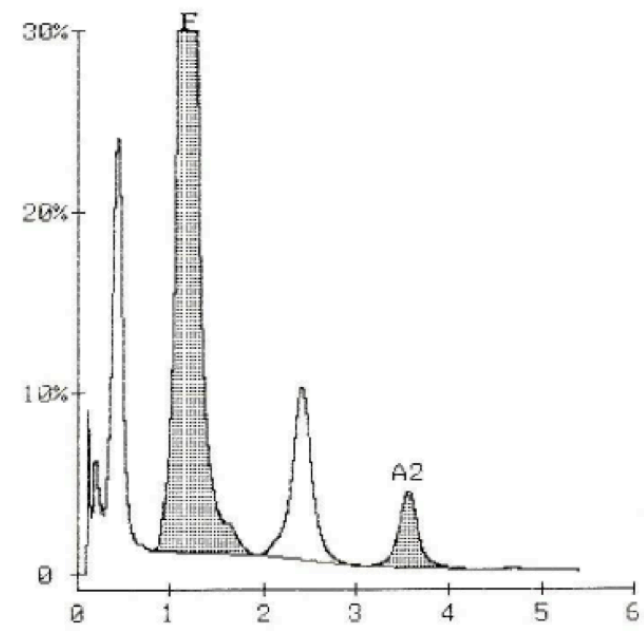

Figure 2 c: HPLC pattern in Thalassemia major

\section{Prenatal Diagnosis}

The only effective way to reduce burden of thalassemia is to prevent birth of homozygotes. Programmes for identification of all individuals carrying a gene for beta Thalassemia, providing genetic counseling of these carriers and prenatal diagnosis where both parents are carriers are important. Several Mediterranean and western countries have achieved a significant change in the homozygote population since the last two decades. Other countries which also have Thalassemia Control Programs include Canada, Israel, Turkey, Thailand, Lebanon, West Bank and Gaza Strip, Malaysia, China, Iran, Egypt, and Pakistan. ${ }^{5}$

Detection of particular molecular defect in both parents is a prerequisite for prenatal diagnosis of the disease. Diagnosis of beta thalassemia can be done by fetal DNA analysis for molecular defects of beta thalassemia or by fetal blood analysis. Fetal DNA for analysis can be obtained from either amniocytes obtained at 15 to 18 weeks or chorionic villi obtained at 10 to 12 weeks of gestation. At present the most widely used procedure is chorionic villi sampling, because of the clear advantage of being carried out during the first trimester of pregnancy. The risk of fetal mortality associated with both methods is in the order of $1-2 \%$. Chorionic villi may be obtained transcervically or transabdominally, the last being most widely used, mainly because it has a low infection rate and a lower incidence of amniotic fluid leakage. ${ }^{16}$
Fetal blood sampling is done by cordocentesis at 18 to 20 wk gestation. Maternal contamination is ruled out using the Kleihauer-Betke method. If no maternal cells are present, it is analyzed by HPLC. The Hb A levels in fetuses affected with beta thalassemia major have ranged from 0 to 0.5 per cent and these were distinguishable from heterozygous babies where the $\mathrm{Hb}$ A levels were $>1.3$ per cent. ${ }^{21}$

\section{Non invasive methods for prenatal diagnosis}

Studies have been done on various noninvasive methods of obtaining fetal DNA from maternal blood. Trophoblasts, lymphocytes and nucleated erythrocytes (NRBCs) are the 3 cell types used as a source of fetal DNA. The cell-free fetal DNA (cffDNA) in maternal plasma are also researched as an alternative to fetal cells for noninvasive prenatal diagnosis. ${ }^{16,21}$ Various methods of preimplantation genetic diagnosis of Beta Thalassemia is also available. ${ }^{22}$

\section{Treatment}

Treatment of beta Thalassemia is life long. Management includes regular blood transfusions, iron chelating treatment, management of complications including osteoporosis, cardiac dysfunction, endocrine problems, hepatitis B and C infection, HIV infection. Without access to regular chelation treatment and medical care, the majority of children with Thalassemia major do not reach the age of $20 .^{23}$

Regular transfusion therapy to maintain hemoglobin levels of at least 9 to $10 \mathrm{~g}$ per deciliter allows for improved growth and development and also reduces hepatosplenomegaly due to extramedullary hematopoiesis as well as bone deformities. Impairment of growth and endocrinopathies, particularly hypogonadism, are common features of thalassemia. This is mainly due to chronic anemia as well as from iron overload. Hormonal replacement is indicated for residual endocrine insufficiency. Hypogonadotropic hypogonadism impairs fertility but can be corrected with the use of hormonal replacement in male patients. A small number of female patients have been able to become pregnant, either spontaneously (if they have received adequate chelation therapy) or with assisted reproductive techniques. Considerable morbidity in older patients results from bone disease due to osteopenia and osteoporosis. Bone-disease management includes the careful monitoring of chelation, lifestyle adjustments (increased calcium intake and physical activity and refraining from smoking), hormonal therapy, and vitamin D therapy. ${ }^{24}$

If the annual red cell requirement exceeds 180-200 ml/ $\mathrm{Kg}$ of splenectomy should be considered, provided that other reasons for increased consumption, such as hemolytic reactions, have been excluded. ${ }^{2}$ Iron overload causes most of the mortality and morbidity associated with thalassemia. Iron deposition occurs in visceral organs (mainly in the 


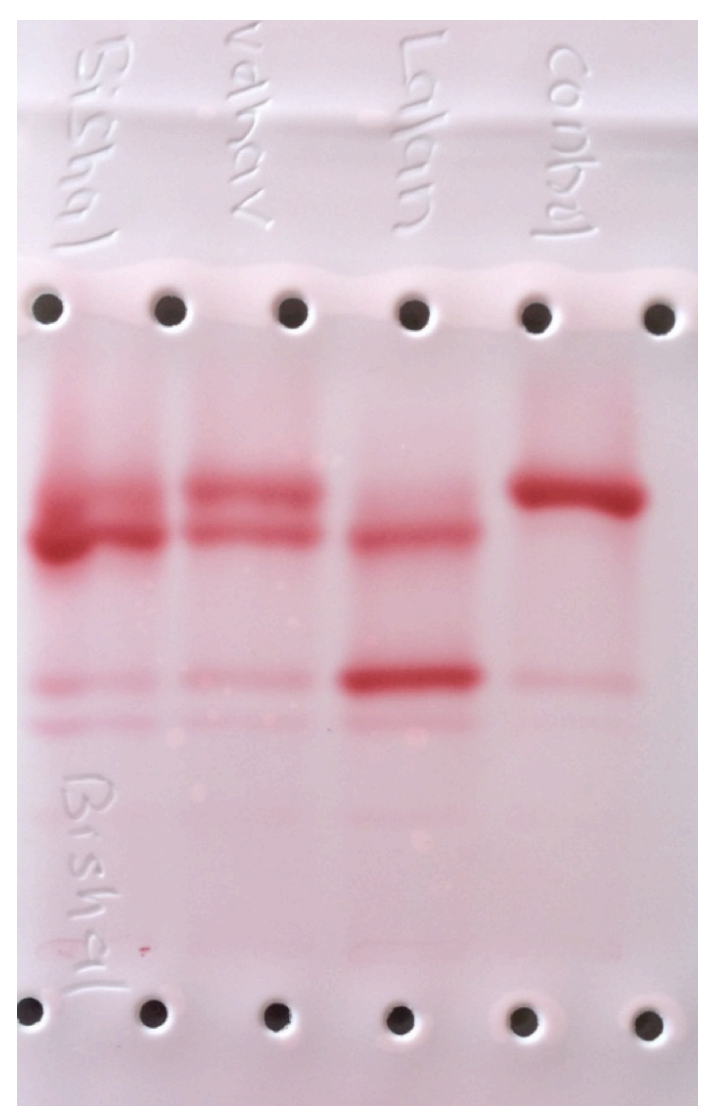

Figure 3: Cellulose acetateHb Electrophoresis at alkaline pH. From right to left , a)normal control with dark band at $\mathrm{HbA}$ position ; b) $\mathrm{HbE} / \mathrm{beta}$ Thalassemia with dark band at $\mathrm{HbA2}$ position and another band at $\mathrm{HbF}$ position; c) beta Thalassemia post transfusion showing band at equally dark band at $H b A$ as well as $H b F$ position; d) beta Thalassemia major with dark band at $\mathrm{HbF}$ and faint band at $\mathrm{HbA}$ position

heart, liver, and endocrine glands), causing tissue damage and ultimately organ dysfunction. An encouraging new approach to chelation therapy is the sequential combined administration of deferiprone and deferoxamine. ${ }^{24}$

Hematopoietic stem-cell transplantation is the only available curative approach for thalassemia, it has been limited by the high cost and the scarcity of HLA-matched, related donors. ${ }^{24}$ The outcome of BMT is related to the pretransplantation clinical conditions, specifically the presence of hepatomegaly, extent of liver fibrosis, history of regular chelation and hence severity of iron accumulation. In patients without the above risk factors, stem cell transplantation from an HLA identical sibling has a disease free survival rate over $90 \%{ }^{2}$ If transplantation is successful, transfusions and usually chelation therapy, are no longer necessary. ${ }^{24}$

Cord blood transplantation from a related donor offers a good probability of a successful cure and is associated with a low risk of GVHD. ${ }^{2}$ Drugs such as 5-azacytidine, hydroxyurea, and various butyrate derivatives to increase the synthesis of fetal hemoglobin. Antioxidants, gene therapies and molecular therapies to correct defect caused by the thalassemia mutation are also under investigation. ${ }^{2,24}$

\section{Prognosis}

Prognosis of thalassemia minor is excellent. An increased risk for cholelithiasis has been demonstrated Patients with thalassemia intermedia who do not usually have severe hemosiderosis are less prone to cardiac problems .However, pulmonary hypertension, thromboembolic complications, overwhelming postsplenectomy sepsis, and the development of hepatocarcinoma may reduce survival in this group of patients. With no treatment, the natural history of thalassemia major patient is was death by age five. With regular transfusion, these patients can survive to second decade and iron chelators have further prolonged survival in recent years. ${ }^{2}$

In developed parts of the world, such as the United States and Europe, there are approximately 10,000 homozygous patients with thalassemia, and the number of new cases has been progressively decreasing because of effective prevention methods. Comprehensive, high-quality medical care is available in these countries, with longer life expectancy and a relatively good quality of life. In contrast, the treatment of thalassemia is entirely different in less developed countries, where safe transfusion and chelation are not universally available. Consequently, many patients with thalassemia in underdeveloped nations die in childhood or adolescence. Programs that provide acceptable care, including transfusion of safe blood and supportive therapy including chelation, must be established. Thalassemia prevention protocols must be developed in these countries, with the use of better education and screening and improved access to prenatal diagnosis. ${ }^{24}$

\section{REFERENCES}

1. Bain BJ. The alpha,beta,delta and gamma thalassaemias and related conditions. In Haemoglobinopathy Diagnosis, 2nd Edition. WileyBlackwell. Oxford; 2006:63-138.

2. Galanello R, Origa R.Beta-thalassemia. Orphanet Journal of Rare Diseases 2010, 5:11. doi: 10.1186/1750-1172-5-11. Crossref

3. Flint J, Harding RM, Boyce AJ, Clegg JB: The population genetics of the hemoglobinopathies. Bailliere's Clinical Hematology 1998;11:1-50. Crossref

4. Vichinsky EP: Changing patterns of thalassemia worldwide. Ann N Y Acad Sci 2005;1054:18-24. Crossref

5. Madan N, Sharma S, Sood SK, Colah R, Bhatia HM. Frequency of Beta thalassaemia and other Haemoglobinopathies in Northern and Western India. Indian J Hum Genet 2010;16:16-25. Crossref

6. Khan WA. Thalassemia in Bangladesh. DS (Children) Hosp J 1999;15:42-4.

7. Ansari SH, Shamsi TS, Ashraf M, Farzana T, Bohray M, Perveen K, Erum $S$ et al Molecular epidemiology of $\beta$-thalassemia in Pakistan: Far reaching implications . Indian J Hum Genet. 2012 ; 18:193-7. 
Crossref

8. Satpute SB, Bankar MP, Momin AA . The Prevalence Of b-Thalassemia Mutations in South Western Maharashtra Indian J Clin Biochem. Oct 2012;27:389-93. Crossref

9. Haig HK Jr, Corinne OB. Molecular basis and prenatal diagnosis of beta-thalassemia. Blood. 1988;72:1107-16.

10. Cao A, Galanello R. Beta-thalassemia. Genet Med. 2010;12:61-76. Crossref

11. Borgna-Pignatti C, Rugolotto S, De Stefano P, Zhao H, Cappellini MD, Del Vecchio GC, Romeo MA, Forni GL, Gamberini MR, Ghilardi R, Piga A, Cnaan A. Survival and complications in patients with thalassemia major treated with transfusion and deferoxamine. Haematologica 2004;89:1187-93.

12. Wheatherall DJ, Clegg JB, editors. The thalassemia syndromes. 4th ed. Oxford, England: Blackwell Science Ltd, 2001.827pp. Crossref

13. Eldor A, Rachmilewitz EA. The hypercoagulable state in thalassemia. Blood 2002;99:36-43. Crossref

14. Taher AT, Otrock ZK, Uthman I, Cappellini MD: Thalassemia and hypercoagulability. Blood Rev 2008;22:283-92. Crossref

15. De Sanctis V, Tangerini A, Testa MR, Lauriola AL, Gamberini MR, Cavallini AR, Rigolin F: Final height and endocrine function in Thalassemia Intermedia. J Pediatr Endocrinol Metab 1998;11:96571.

16. Rosatelli MC, Saba L.Prenatal Diagnosis of $\beta$-Thalassemias and Hemoglobinopathies. Mediterr J Hematol Infect Dis. 2009; 1.

17. Lacerra G, Scarano C, Lagona LF, Testa R, Caruso DG, 27. Medulla $\mathrm{E}$, et al. Genotype-phenotype relationship of the $\delta$-thalassaemia and $\mathrm{Hb} \mathrm{A}(2)$ variants: observation of 52 genotypes. Hemoglobin

\section{0;34:407-23. Crossref}

18. Wajcman H, Moradkhani $\mathrm{K}$ : Abnormal haemoglobins: detection \& characterization. Indian J Med Res. Oct 2011;134:538-46.

19. England JM, Fraser PM. Differentiation of iron deficiency from thalassemia trait by routine blood count. Lancet 1973;1:449-452. Crossref

20. Sujatha R, Sreekantha, Niveditha S R,Avinash SS, Remya,Vinodchandran, Rangaswamy R. The study of recent biochemical and pathological aspects of thalassemia. International Journal of Research in Health Sciences 2013;1:142-53.

21. Colah R, Gorakshakar A, Nadkarni A. Global burden, distribution and prevention of $\beta$-thalassemias and hemoglobin $\mathrm{E}$ disorders. Expert Rev Hematol. 2010;3:103-17. Crossref

22. Hussey ND, Davis T, Hall JR, Barry MF, Draper R, Norman RJ, Rudzki Z. Preimplantation genetic diagnosis for $\beta$-thalassaemia using sequencing of single cell PCR products to detect mutations and polymorphic loci Mol. Hum. Reprod. 2002;12:1136-43. Crossref

23. Petrou M. Screening for beta thalassaemia. Indian J Hum Genet 2010;16:1-5. Crossref

24. Rund D, Rachmilewitz E. $\beta$-Thalassemia. N Engl J Med 2005;353:1135-46. Crossref 